\title{
Local governance in China: realizing the citizens' rights of migrants
}

\section{Chunguang Wang ${ }^{1}$}

Received: 21 November 2017 / Accepted: 15 February 2018 / Published online: 25 June 2018

(c) Springer Nature Singapore Pte Ltd. 2018

\begin{abstract}
Previous research has considered government behavior as a single phenomenon and researched the impact of governance on the realization of migrants' citizens' rights from the point of view of the political system and policy. But in fact, the government is a complex system in which there are differences not only between agencies, but also between different levels of government, and the latter in particular has an important impact on the citizenship rights of migrants. This paper uses education and health to observe the role of different levels of government in determining the citizenship rights of migrants and the mechanisms that shape their attitudes and behavior. It argues that in implementing central policy local government engages in the strategies of "interpretation and adaptation" and that their use of these mechanisms is dependent on local welfare and related conditions.
\end{abstract}

Keywords Governance $\cdot$ Citizenship rights $\cdot$ Migrants $\cdot$ Interpretation and adaptation $\cdot$ Local welfare

\section{Introduction}

Beginning in the 1980s, rural-urban migrants became a special population group associated with processes of industrialization and urbanization in China, reflecting the unique pathway that the nation took from a planned to a market-based economy. Large numbers of migrants went to the cities, flooding into the developed coastal areas. This caused extreme panic and unease among urban residents and governments. At the time migrants were referred to as "blind floaters" (mangliu). Some researchers pointed out that in earlier periods of history such "blind floaters" had led to the fall of dynasties and on the basis of this they made very negative judgments

English translation by Jennifer Holdaway.

Chunguang Wang

wangcg@ cass.org.cn

1 Institute of Sociology, Chinese Academy of Social Sciences, Beijing, China 
about migrants, causing the government to be even more worried and uneasy. Of course, many other scholars also explained the causes of migration and patterns of mobility from the point of view of economics and sociology in order to devise effective methods for managing migration flows and achieving "orderly migration". "Orderly migration" became a term that was widely used in academia and by government in the mid-1990s. Later, researchers pointed to the phenomenon of migrants "returning to the countryside to start businesses". They thought that a wave of return migration and entrepreneurship was already in progress and called for the government to step up policies to attract migrants back to set up businesses in their places of origin.

But no matter whether they were viewed as "blind floaters", as "orderly migrants" or as "returning entrepreneurs", behind all of these terms lay a set of common anxieties: that migrants were a potential threat to order in the cities; that they should be kept out of the city; and that the city was never going to be their place of long term residence or their emotional "home". Behind this was the common assumption that migrants would never have citizenship rights in the city.

The state's ideas about the management of migration underwent a clear shift in 2001 and migrants came to be accepted as members of urban society. In 2006, the State Council specifically issued the "State Council Guiding Thoughts and Principles on Resolving the Problem of Migrant Workers" (2006:5), which stated for the first time that migrants entering cities to engage in work and start businesses was a necessary requirement of China's modernization, and stipulated 18 specific policies to deal with the problem of migrant workers (including employment services, technical training, protection of social rights and social protection) (Zhang 2009). However, 8 years have passed, and despite this change in attitude, and the adjustment of social policies, migrants still do not enjoy the actual benefits of citizenship in urban areas. In the last 10 years or so, what the government has mostly done has been to indicate some policy directions (zhengceyindao), and although it has brought out quite a lot of new social policies, many of them have not actually been implemented.

From education policy to labor contract law to social rights, the government has required local governments (in particular local governments in receiving locations) to include migrants in the scope of social policy and provide related rights and benefits. But a survey we conducted found that even though $97 \%$ of the migrants interviewed felt that the city was their home, they did not have the same rights as local residents or receive the same treatment. ${ }^{1}$ Only $28 \%$ were enrolled in pension insurance in the city they lived in, only $29.7 \%$ were enrolled in worker health care insurance, only $3 \%$ were enrolled in urban health insurance, and only $11.5 \%$ had housing benefits, etc. At the same time, we found that the rights and benefits that migrants enjoyed were different in different cities. In particular, cities in the hinterland were better than the coastal cities. This led us to ask why it is that the central government has required that migrants have the same rights and benefits as urban residents, but

\footnotetext{
1 A survey on migrants' social integration in eight cities in 2013, implemented by National Health and Family Planning Commission with collaboration from Institute of Sociology at Chinese Academy of Social Sciences, Renmin University of China, and Tsinghua Univservity.
} 
they do not enjoy them; and why it is that migrants in different cities receive different treatment. Rural-urban migrants account for about $80 \%$ of all migrants. It cannot be denied that the governance style, goals and circumstances of local governments definitely play an important role and these are the questions with which this article is concerned.

\section{Local governance: a crucial perspective for research on social inclusion}

There are already quite a lot of theories that attempt to explain the integration of migrants into cities, including the dual rural-urban system theory that focuses on the residence (hukou) registration system, theories of social discrimination, theories of citizens' rights, theories of social segregation, theories of class segmentation, and theories of urbanization. These theories all have some explanatory power but they also have limitations. In particular, in their approach to the government they all assume that the government is a single entity and they overlook the role of different levels of government and differences in their attitudes and behavior in dealing with the problem of integrating rural-urban migrants. But we think that although the central government still has to do more to ensure that migrants receive equal treatment, even if it does this, many policies will not be effectively implemented. For that to happen, local government has to play a crucial role.

According to theories of citizens' rights, migrants should have the right to be integrated into urban society as citizens. Enabling them to integrate should be the responsibility of each level of government and local government systems should carry out this responsibility. Central government documents have gradually adopted this approach in principle, and no longer say that migrants should not enjoy basic rights in the city. According to citizenship theory, government is not the only provider of rights, but the rights that the government provides should be equal for all citizens and should not be different or discriminatory. In his theory of citizenship, the English sociologist Marshall (1950) proposed that citizens' rights include social rights, political rights and citizens' rights, which are most clearly embodied in specific rights to education, political participation and property rights. The responsibility of local government is mostly to make sure that citizenship rights are made effective for every citizen, and that every citizen has equal rights.

The Commission on Global Governance states that "governance" is the combination of the efforts of individuals and systems and of the public and private agencies to manage their common affairs. It is a special process, and in the course of it, conflict and different interests can mutually adjust to each other and can also engage in cooperative action. Governance includes both formal institutional arrangements and informal arrangements. From this it can be seen that the subjects of governance are diverse, and that there can be mutual cooperation and balancing between them; also that the subjects of governance are at the same time its objects. That is to say that government, society and citizens are both governors and governed. According to governance theory, citizens' rights are not given, they are taken. Therefore, when it comes to the specifics of migrants' rights in the city, it is not a question of 
waiting for the government to give them, but migrants need to take these rights for themselves. The American scholar, Dorothy J. Solinger sees the actions of migrants in Chinese cities as "taking citizens' rights" (2009). This perspective is very interesting and it is valuable for observing the situation of migrants in China. However, is it really the case that migrants can claim the citizens' rights they seek, or protect them in the way that she says? Or that they can establish other citizens' rights? It is clear that she has not given an affirmative answer to this question.

In theories of citizenship, the relationship between the state, society and the market is one of the most widely used analytical frameworks. But in China's particular political scenario, the state is not monolithic, but composed of many different levels. Even with the concentration of power at the Center, each level of government still has a certain amount of room for maneuver. In many situations local governments have both the room and the power to "adapt" policy. This is reflected in the common saying that "those at the top have policies, but those below have responses" (shang you zhengce, xia you duice). "Those below have responses" mostly refers to the fact that lower levels of government have various ways of dealing with the requirements and policies of higher levels of government. In the language of governance, the central government transmits services to the people through various layers of government (these are the rights that every citizen gets). However, in the process of this transmission, different levels of government have some space, and some power; it is not just a simple process of transmission. We refer to this space and power as "interpretation (jiedu) and adaptation (biantong)." Although the central government has not entirely resolved the problem of citizens' rights for migrants in urban society, it has made efforts in the direction of improving them. But because local governments have the space and power to interpret and adapt central policy, they have the opportunity to implement policies towards migrants in a way that constructs them in accordance with their own wishes and interests and in this way they also affect the efforts of the central government.

The levels of government in China are as follows: the central government, the provincial government; and the sub-provincial government. The latter includes the city government (and beneath it the district, street and community governments and the residents' committee) and the county government (and beneath it the township and the administrative village). Of the nine levels of government in the system, the ones that interact most directly with migrant workers are the township, the street and the community (or administrative village) and the residents' committee. But these levels do not have policy making powers. Only governments above the level of counties and cities have decision making power. The more decision making power a government has, the less likely it is to interact with migrant workers and the greater its distance from actual management of migrants.

Because of this the policy requirements and goals of the central government rely on local government for their implementation and realization. But in the process of implementing policy, provincial capitals and county town governments will engage in interpretation of policy in accordance with their own intentions and needs and in this process of interpretation there is the potential for adapting policies. Our research found that county and municipal level governments have the most specific, clear and direct influence when it comes to interpreting, specifying and implementing policies that relate to the citizens' rights of migrants. In different cities and municipalities, 
migrants' specific situation is different: at the same time, within the same city, the role of street level government is smaller, and city and district governments have the most direct and direct impact on policy implementation.

Many factors affect the intentions and actions of these levels of government when it comes to decision making, including their ideas about governance, economic structure, social traditions and the current situation of migration. Of course, ideas about governance may also be constrained by economic structure and social traditions but sometimes they can also exercise a considerable independent influence. Factors relating to economic structure, including whether or not the secondary and tertiary sectors are developed, the scale of enterprises, the type of ownership and the structure of industry types, all affect how local government treats migrants from outside. Social traditions include language, lifestyle, local attitudes, etc. Characteristics relating to the composition of the migrant population, including level of education, place of origin, concentration of residence and type of housing, the type of occupations in which they are employed, etc., will also affect local governments' governance behavior. Therefore, we think that in exploring the question of migrants' rights from the point of view of policy and institutional factors, three dimensions need to be considered.

\section{Types of local governance model}

The first dimension is the question of national policy and system-related barriers at the central or higher level that have not yet been resolved.The second dimension, which becomes relevant when policy and system-related problems have already been resolved at the central or higher level, is the question of barriers to implementation at the level of the county or municipality. The third dimension is the problem of policy and institutional issues that have been resolved at the higher level being reconstructed (in a different form and with different implications from the original intent), at the municipal or county level.

Local governments' attitudes and behavior with regard to the integration of migrants can be evaluated from a number of different perspectives. However, in the context of China's current situation, for the majority of migrant workers, the most important aspects of social integration are whether or not they are eligible for residence registration and whether or not they enjoy social welfare benefits. Here we will analyze the impact of different local governance models on the integration of migrant workers from two dimensions. We distinguish four types of governance model according to whether local government has an open inclusive attitude toward migrants and whether or not it provides equal access to social welfare benefits (services). The four types are market-open, market-control, service-control, and serviceopen, as shown in Fig. 1.

In China, to see whether a local government is open towards migrants, we need to look closely at its hukou (permanent residence registration) system. Over the last 30 years of reform and opening up, the basic nature of the urban hukou system has not changed a great deal, but there have been some clear changes in its form. First there was the introduction of the blue stamp hukou and the red stamp hukou. Later there was the temporary residence permit and now there is 
Commodifying

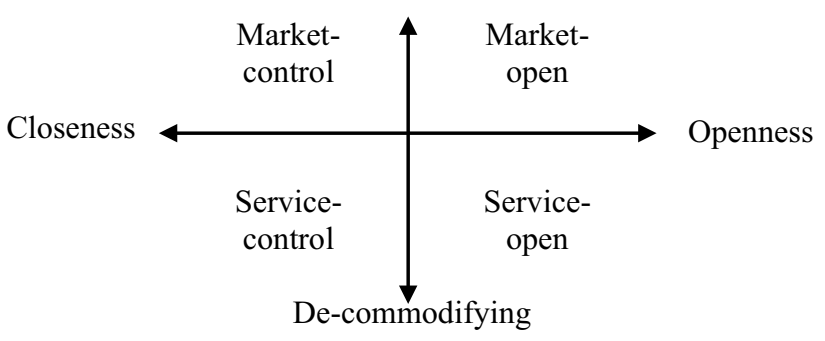

Fig. 1 Four models of local governance

the residence permit. We can see that some cities are still using the temporary resident permit system while other cities have adopted the resident permit; and in some cities it is easier to get a hukou than it is in others. In some cities it is easier for migrants from within the same jurisdiction to convert to an urban hukou than it is for migrants from outside its jurisdiction. All these things are indications of how open the governance of a local government is to migrants.

Directly related to hukou eligibility is the state of social welfare benefits. In China, the biggest difference that an urban hukou brings is the difference in the level of social benefits that can be enjoyed. In general, whether or not a person has an urban hukou determines whether or not they can enjoy benefits including social protection, education, healthcare and housing, etc. Of course, with changes in the form of residence registration, the relationship between eligibility for hukou and social benefits has also undergone some change. Having a temporary residence permit or a residence permit did not necessarily mean that you would enjoy social welfare benefits. Different governments gave different social welfare benefits along with the temporary residence permits and residence permits. So there began to be a separation between eligibility for an urban hukou and social welfare benefits (Shogo 2011, p 16).

Social policies have the effect of de-commodifying the labor force in the sense that they reduce workers' dependence on the labor market. There are at least three providers of social welfare benefits (enterprises, social organizations and the state), of which in many countries the state is the most important. In China, when we talk about social welfare benefits they are mostly provided by the state and they have an important effect in de-commodifying workers. Because of this, if migrants enjoy social welfare benefits in the city, then this means that their lives are less dependent on the market, or that to some extent the city has reduced the impact of marketization and commercialization. On the other hand, if migrants do not enjoy social welfare benefits, this means that their lives are dependent on the market, or one could say that they are completely commodified. Because of this, we consider openness and commodification to be the two dimensions that form the matrix of four types of local government governance styles. 
The market-open governance model means that the government does not provide any social welfare benefits, and urban hukou status can be bought. Of course, the price is high but if you have money then you can acquire an urban hukou. However, having a hukou does not mean that you can enjoy government-provided welfare benefits; these also depend upon your ability to buy them in the market place. In the past, some cities sold a "blue stamp"hukou to migrants from outside, but having this blue stamp hukou did not mean they had access to governmentprovided social welfare benefits. Some city governments still have a policy under which you can acquire a hukou by buying a house, but this does not mean that you are eligible for social welfare benefits. This also belongs to market-style governance. In contrast, a market-control model of governance is one in which it is very hard to get a hukou. Even if you have money you cannot buy it, and migrants' social welfare benefits are not provided by the government but have to be bought in the market. As we will see, many big cities fall into this category.

Market-open and market-control models of governance have a common characteristic, which is that the government does not provide welfare benefits to migrants. Service-control and service-open models of governance are similar in the sense that in both cases the government does provide services, but the service-control type is not as good as the service-open type. In the service-control model of governance, the government uses access to services to control migrants' eligibility for the hukou in accordance with its needs. This model is not at all open and in general it is very difficult to get a hukou. However, if you do, then you can enjoy benefits provided by the government; otherwise, you cannot. This is the old style of governance in China, in which hukou and benefits are tied to each other (See Table 1). In contrast, with the service-open type governance, there are no barriers to acquiring a hukou and nor are there any barriers to enjoying government provided benefits.

The four kinds of local governance are not just an abstract, logical typology. The basic thrust of China's reform and opening up has been in the direction of marketization, industrialization, and urbanization. Because of this, the flow of rural labor and population has also always been in the direction of the marketand industrialized and urban areas. In this process, in policies dealing with migrants, cities have undergone some changes and as a result, historical and regional factors have interacted to produce different styles of governance.

The market-open type appeared in some cities in the 1990s and manifested itself in cities using market mechanisms to sell blue stamp hukou permits. Although different places had different prices, they were all very high and not all migrants could afford them. But later, because migrants discovered that these blue hukou did not bring any benefits, they lost interest, and the blue hukou fizzled out. The marketcontrol mode of governance is a method that is used to deal with market competition, and basically appeared after the market-open type, mostly in big cities and mega cities. Some cities used offering urban hukou to those who bought houses or paid tax as a way to attract wealthy rural people and employers to the city. But those who got hukou could not necessarily enjoy benefits similar to those of city residents; they may have only received a few specific benefits, like children's education. This method is still in use in some cities. 


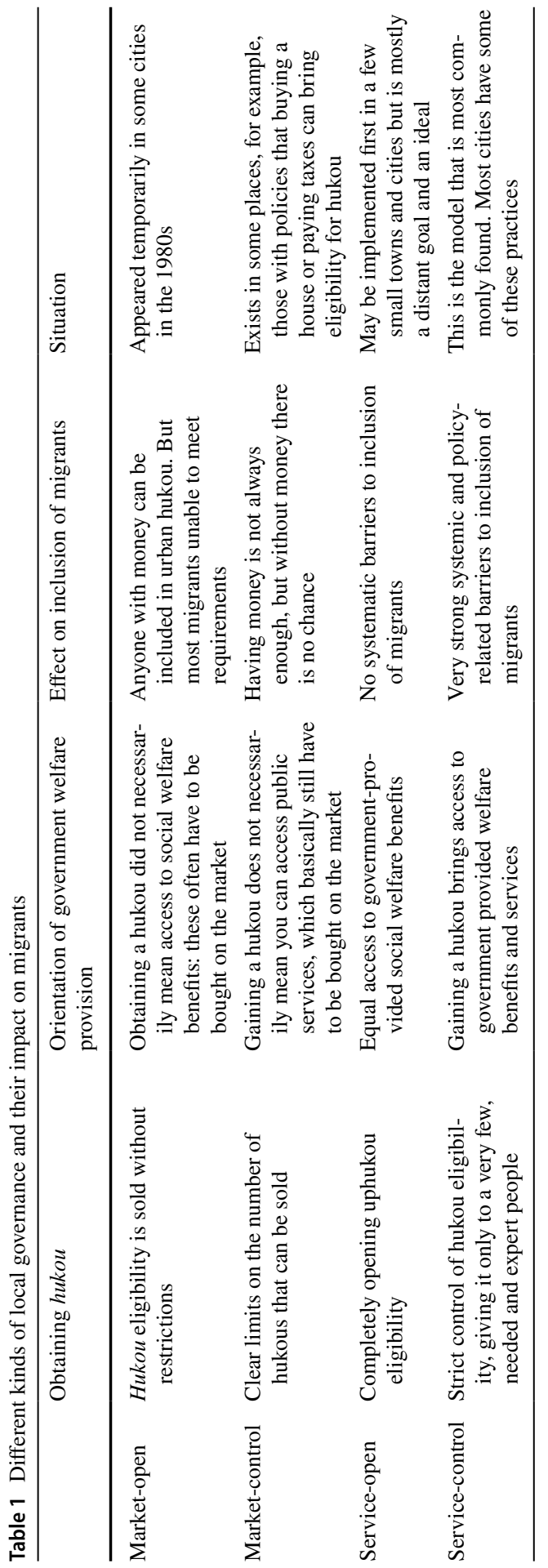


The service-control model of governance is a common practice that has continued from before reform, and it involves cities giving an urban hukou to an extremely small number of people, who almost cannot be counted as migrants because even people who have been rated as outstanding migrant workers cannot enjoy this treatment. The service-open model is the goal towards which the state is working, to establish a society and state in which everyone can enjoy equal social benefits, regardless of whether they are in the city or in the countryside. Under this model, their location, and migration status will not affect their access to social benefits. From this we can see that these four models of governance have had a changing relationship over time (see the diagram below): from service-control, passing through market-open and market-control, and now the goal is to establish a service-open model of governance.

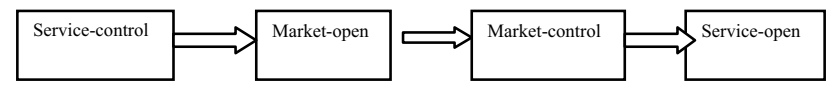

On a superficial level, it seems as if China is a country in which power is highly concentrated and also that China has only one governance model, but in fact that is not the case at all. But is it possible that different governance models can appear in a country in which power is highly centralized? And how does this manifest itself in terms of governance models relating to migrants' integration? What kind of relationship and connection is there between the governance models of different cities? These are all questions that we explore further below.

\section{Case study analysis of different local modes of governance}

This section looks at the four big cities of Shanghai, Beijing, Guangzhou and Wuhan and examines what they have done in terms of implementing policies towards the integration of migrants in order to discuss the question of the role of governance and its impact on the integration of migrants. These four cities all have populations of more than 10 million (including both residents and migrants) of which migrants make up around a third. From this we can see that they are not just big cities but also among the cities that are receiving the most migrants. The way in which they treat migrants will therefore have a certain impact on the integration of migrants generally.

In the last ten years, national government policy towards migrants has undergone a clear change (Zhang 2009). Research shows that the State Council "Opinions on the Problem of Migrant Workers" proposed 18 specific policies regarding three issues: employment services, social rights and social protection, with rural-urban migrant workers as the main group of migrants addressed. In other years the State Council and other government agencies have already brought out a series of policies relating to migrants' housing, education, healthcare, employment, rights protection and social protection. Although these policies have not explicitly regarded migrants as urban residents, they have nonetheless demonstrated a clear equalizing trend 
towards allowing migrants to enjoy similar treatment to urban residents to the extent possible. Below we examine how these four cities have gone about implementing these policies?

Until now, although the government has carried out some reforms to the hukou system, for example opening up small towns and cities, overall, they have not reformed the hukou system in a comprehensive way. Everyone, from the central government to local governments, realizes that hukou reform is something that has to be done because migrant workers have made an enormous contribution to the development of cities. Even though there is no pressure from the central government, migrants' demands for urban residency have become stronger and stronger. And according to international practice and the government's advocacy of ideas of social justice, the mega cities are facing tremendous pressure to open up residency rights. Because of this, some megacities have carried out some very small pilot programs, for example changing the temporary residence permit into a residence permit, and some have initiated point-count systems for acquiring an urban hukou. In the four cities in which we carried out research, three have already instituted residence permits, and two of them have introduced point-count systems.

The threshold for residence permits is quite low but the threshold for the pointbased hukou is very high and more or less out of reach for rural-urban migrants. For example, Guangzhou introduced the residence permit and point-count system in 2010. The city stipulated that"migrants who have lived in the city and run businesses for more than 6 months, or who meet the conditions stipulated by the local government, will be given a residence permit valid for a maximum of 3 years on production of an employment or business permit from the public security bureau in their place of residence or the township or street migrant management organization. Migrants who do not meet these conditions will be given residence permits that are valid for no more than 6 months."

The residence permit is an improvement over the temporary residence permit because the bearer of the residence permit can enjoy some public services and social welfare benefits, and after a certain number of years there is the possibility for the bearer to obtain an urban hukou. For example, Guangzhou City stipulates that holders of a residence permits can in theory enjoy professional training, legal assistance, family planning services, participation in social protection programs, immunization and disease prevention. They can also hold drivers' licenses and apply for permits to travel to Hong Kong and Macao. Only permit holders who have lived in Guangzhou for 5 years have the same rights in terms of compulsory education for their children as local families. The policy further stipulates that "holders of a residence permit who live continuously in the same place and pay social insurance fees for a period of 7 years, and who have a stable place of residence and stable employment, and who are in compliance with family planning policies and pay tax according to the law and who do not have a criminal record" can apply for a permanent hukou. The total number of hukou issued each year will be controlled and, they will be processed according to the conditions of the applicant, with skilled people having priority. In this case, the cap on total numbers and the point system basically keep migrants outside the threshold. In 2011, Guangzhou only gave out 3000 hukou on the basis of the point system, and there are more than 6 million migrants in the city. Nearly all the 
resident permits based on points were used to bring in skilled people from outside the city.

In 2002, Shanghai introduced a residence permit system, making it the first city to do so. At the same time, it ended the blue stamp hukou policy. At first, the residence permit was only given to skilled people from within and outside China that the city really needed. It was called the "talent" residence permit (rencaijuliuzheng) and divided into Class A and Class B. The first day that it came into effect, only 60 people got it, and the quota for the first year was only a few thousand. However, by the end of 2001, there were about 48,000 foreign experts in Shanghai from foreign countries and from Hong Kong, Macao and Taiwan, accounting for about a quarter of all experts in the whole country. There were also about 20,000 foreign students who used "soft migration" to return home for a short time and then come to Shanghai to work. ${ }^{2}$ On May 20, 2013, Shanghai municipality issued the "Shanghai Residence Permit Management Methods" which extended the coverage of the residence permit to all outsiders who had a legal residence and legal and stable employment, as well as to those who were living with family or friends, studying or taking advanced courses for more than half a year. This was different again from the former residence permit but it still retained some of the same practices and content, such as the fact that not all people who held a residence permit could enjoy the public services available in Shanghai.

The resident permit point system allocated points for residence permit holders who had stable residence and employment in the city, using a system of indicators that was set up to translate individual characteristics and contributions into point counts. As the permit holder's number of years of residence and employment, as well as social insurance contributions and education and employment history increased, he or she would accumulate more points. When the points reached a certain level, the permit holder could enjoy commensurate social services. The system of indicators included basic characteristics such as age, educational background, technical expertise and career grade, and number of years working and paying into social insurance schemes in the city. Then depending on the economic and social development of the city, and the need to manage the provision of services, additional points could be added or deducted. There was also a "one vote veto system". Within each set of indicators, specific standards for accumulating points were set according to different situations. ${ }^{3}$ Later, Shanghai introduced the "Measures for Implementing the Shanghai City Residence Permit Point System".

From the regulations it is clear that the probability of migrants' accumulating enough points to be eligible for a hukou would be extremely low. The probability of their acquiring points on indicators that gave extra credit, such as educational background and technical expertise, would be incredibly low because the threshold

\footnotetext{
2 "From temporary residence registration to long-term residence permit-Shanghai is going to be a 'migrant city' again,"Shanghai Youth Daily, September 17, 2002. http://finance.sina.com.cn/g/20020 917/1122255836.html.

${ }^{3}$ Government of Shanghai: Measuresfor Management of Shanghai Residence Permit. May 20, 2013. http://218.242.131.185/jzzsb/pingfen/zc1.jsp.
} 
was too high. Only a very small number of rural migrants who were eligible because they had started businesses and become employers, or who had acquired technical skills, could reach these standards. So Shanghai did open up a pathway from the usual residence permit to a permit based on the accumulation of points, and it also opened a pathway for turning the residence permit into a permanent urban hukou. However, because it set very high thresholds at both crucial points in the pipeline, it meant that the vast majority of migrants had no way to reach them, and because of this it greatly reduced their chances of obtaining a permanent urban hukou.

The level of openness of the hukou system in Wuhan is a little greater than in Guangzhou or Shanghai. The opening up of Wuhan's hukou system has also taken place gradually and taken three forms: first a temporary residence permit, then a residence permit and then permanent urban hukou. Our survey showed that only $54.3 \%$ of migrants had processed residence permits and $15.8 \%$ had processed temporary residence permits, and some had neither. In Wuhan, the threshold for processing a residence permit is not high. The only requirements are to have a legal residence and a stable job, and there are no extra conditions between the holding of a residence permit and receiving social services. Basically, all migrants who have a residence permit can enjoy basic social services, participate in social insurance and their children can take part in compulsory education. Those who have held a residence permit for 7 years or more can become permanent residents of the city.

At the same time, migrants can also obtain a local hukou in Wuhan through the following paths: marriage, following parents or children, and setting up businesses. Those who have graduated from university or technical school (zhongzhuan) and who have taken employment and bought houses in the city can also obtain an urban hukou. For many migrants, buying a house is the most feasible way to acquire a hukou. The Wuhan rules stipulate that "people who buy houses in the city center that are more than 100 square meters in size or cost more than 500,000 yuan, or who buy houses in the outer city that are more than 90 square meters in size and cost more than 300,000 yuan can obtain a city hukou". However, most migrants are not in a position to do this, especially those who do not have the economic means to buy a house.

Although Beijing has a residence permit policy, it is basically only for skilled people and not a policy for all migrants. That is to say, Beijing still does not have the policies that have been initiated in the three other cities. One could say that Beijing's current residency policy is similar to Shanghai's earlier policy. It was issued on June 24, 1999 and its full title is "Temporary Measures for Beijing City to Bring in Skilled People (Beijing Work and Residency Permit)". ${ }^{4}$ So more accurately it is an employment and residence permit that is given mostly to skilled people that the city urgently needs. It has a very high eligibility threshold. For example, the first condition is that the applicant must have a university education and have high-level technical or professional or management expertise, or they must a Master's degree

\footnotetext{
${ }^{4}$ Government of Beijing: Temporary Measures for Beijing City to Bring in Skilled People (Beijing Work and Residency Permit). June 24, 1999. http://wenku.baidu.com/view/34dbbf80bceb19e8b8f6ba11. html.
} 
from a domestic or foreign university. They must also be under the age of 45 and in good health. Clearly, rural-urban migrants are not in the range of those covered.

From the extent to which hukou eligibility is open to migrants from rural areas in the four cities we can see that Beijing is the least open. Wuhan and Guangzhou are more open but still have a high threshold. In order of openness the four cities would rank Beijing, Shanghai, Wuhan and Guangzhou. So they all have residence permits but the content is different. The Beijing residence permit is different in its basic nature from those in the other cities in that the latter are directed at all migrants while the former is directed at bringing in skilled people. But even in the three other cities the residence permit brings different social benefits. In Wuhan, as long as you have a residence permit you can enjoy local social welfare benefits. But in Shanghai, it is not the case that you only have to have a residence permit to get benefits; you also have to accumulate a certain number of points before you get public services. So the permit is just a basic condition on top of which you have to accumulate points. Guangzhou has four types of residence permit, less than 6 months, 6 months to 3 years, 3-5 years, and more than 5 years. And the public services that you can obtain with the first three are different from those that accompany the last one. For example, people who have lived in the city for more than 5 years can take advantage of compulsory public education, and, in principle migrants who have lived in the city for a long time can apply for a hukou, although the quota is limited.

From this analysis, we can see that the four cities' style of governance is very different. Beijing strictly controls access to the residence permit, and so it belongs to the control type of governance. But once you have a residence permit you get the same public services and social welfare benefits as urban hukou holders, so it belongs to the service-control type. Both Shanghai and Guangzhou have set up pathways for migrants to become urban citizens. In Shanghai people get residence permits and accumulate points and then can finally obtain a hukou. In Guangzhou there are different kinds of residence permits for people with different lengths of residence and this is how you accumulate points and gain a hukou. So both these cities can be seen as limited service-control types that are to some extent more oriented towards openness than Beijing. Wuhan is a market-control type, which is to say that as long as you have the economic wherewithal, and can buy a house in Wuhan, then you can be eligible for a hukou. At the same time, as soon as you get a residence permit you can enjoy some public services. But in fact, Wuhan has still not enabled migrants to enjoy the same public services as residents, because some migrants still do not have residence permits and only have temporary residence permits, and the two types of permits are different in terms of the access to services that they provide.

\section{Local government mechanisms for "interpretation and adaptation"}

Why are the same policies implemented in different ways in different places? And why do some local governments introduce their own policies even when the central government has not done so. This relates to the issue of center-local government relations. Zheng Yongnian is of the opinion that in China, "although the central government as the policy making body is constantly bringing out new policies, 
local government can always find reasons for not implementing central policies, or for implementing them in a selective fashion, and this depends on the extent to which central policy is in accordance with local interests"(Zheng 2013, p 10). Zheng uses the term "behavioral federalism" to describe the relationship between central and local government in China, and he argues that the mechanisms behind this are "force, negotiation, and mutual benefit"(Zheng 2013, p 10). He does not discuss the way in which local governments selectively implement central policy and the mechanisms behind this, but I think that the reason why we find different types of local governance with regard to the treatment of migrants, is because each locality engages in the "interpretation and adaptation" of "central policy".

"Interpretation" is when local government explains or understands central policy according to its own concerns and interests. In the policies of the four cities towards migrants discussed above we can see the broad direction of central policy in the area of hukou reform, social protection, compulsory education and other policies. But at the same time there are also some clear differences. These may be caused partly by the fact that central policy is not entirely clear, but to a great extent they are also caused by local governments' "interpretation and adaptation" and it is these that we are concerned with here. Our in-depth analysis found that at least three types of interpretation and adaptation can be distinguished: experimentation, suspension, and pre-emption (shiyan, xuanzhi, yushe).

Hukou reform in all the four cities belongs to the category of experimentation. Although the central government has made some rules about hukou reform in principle, they have not made any specific policy requirements of Shanghai, Beijing, Guangzhou or Wuhan. Shanghai and Beijing established policies for attracting skilled people with a residence permit as early as the 1990s and the residence permit policy is an extension of this. Later, Guangzhou introduced the point system, which to some extent deepened and expanded the residence permit system. It also established a very narrow pathway between the residence permit and the hukou. Still later, Shanghai instituted a similar system to Guangzhou's. These two cities have a different threshold, and there are clear differences in the social welfare benefits that are attached to the residence permit. In China's reform and opening up, the experimental practices that are taking place in various localities are in most situations permitted, or at least tolerated by the central government, and experience tells us that China's reform has always started at the local level. It has always been tried out in practice at the local level and then following "high level design" it is rolled out as a national policy, and implemented throughout the country (Zheng 2013).

As this article has indicated, in the last 10 years, the central government has gradually introduced a series of social policies relating to migrants, including social protection, compulsory education, labour rights, and professional training policies. In the late 1990s, the Education Ministry introduced the policy of the "Two major responsibilities" (liangweizhu) with regard to migrant children, but up to now the way in which different places have implemented this policy is different. In a number of places, it is common for the policy to have been "suspended" (xuanzhi). Beijing and Shanghai have clearly different policies when it comes to their treatment of migrants' children. We can see from the statistics that the percentage of migrants' children in public middle and primary schools is more than $60 \%$ in both 
cases. However, quite a lot of migrants' children remain in community migrant-run schools. Shanghai's policy towards migrant schools is to give the average student per capita subsidy to these schools and to improve their teaching and learning conditions in terms of hardware and software.

In Beijing, although some migrant schools that have been certified as eligible to operate do receive some subsidies, they do not get the average student fee. Very few schools have been able awarded eligibility for funding and even some which are considered to have the conditions to run a school have not been certified and are remain "illegal schools". What is even more worthy of note is that the reason why a high percentage of migrant children attend public schools in Beijing is because Beijing City banned migrant-run schools, with the result that that some migrant children had no school to go to and had to leave Beijing. Recently, the government of one district in Beijing issued a notification that in order for migrant children to take more advantage of compulsory education, they would ban all migrant schools that were not up to standard or which had not been given permits. As a result, 39 schools were forced to close. The students who were attending those schools could not find public schools that were willing to accept them. Some parents took their children to public schools and requested that they be allowed to attend but they were told that these schools had not received a notification that they were required to accept their children. Some parents in better economic circumstances used connections and paid "support" fees and only then they were able to get their children into public schools, but more parents took their children and went to work in districts and counties that have migrant schools or sent their children back to the countryside.

One non-profit migrant school in that district, which was started with support from an entrepreneur, provided free compulsory education for migrant children. This school used the former dormitory of a public school, and the quality of education had already reached the requirements of the district education bureau. But although the relevant education officials emphasized that this school had already met the standards, it still was not given a permit. In the recent round of closings, this school was still not closed, but because it did not have a permit, it was hard for it to get educational subsidies. The head of this school graduated from one of Beijing's universities, and had set up a small enterprise and made some money. He said he was also from the countryside originally. He had been to the school and seen the living conditions of the students and found that the original headmaster could not continue anymore and was planning to give up. If this had school closed the migrant children in the area would have had no opportunity to go to school, and sympathy prompted him to take on the job of headmaster. He has already done it for 8 years, but now he is also on the point of giving up. From this we can see that migrant schools that have been found to be not up to standards are often closed or demolished, and that once they are demolished migrant children find it hard to get into public schools. Furthermore, even those migrant schools that can meet the standards find it very hard to get a legal permit, which leaves the door open for the government to demolish them in the future. This creates a situation in which migrant children cannot have a stable situation to live and develop in the city.

In Guangzhou, when migrant children go to public schools they basically all have to pay some fees. Although these fees are not formally announced, in fact, migrants 
are required to pay them or their children cannot get into school. Quite a lot of migrants send their children to private schools. These private schools are different from migrant schools; their fees are higher, and of course the conditions are also a lot better. But the majority of migrants do not have the economic resources to send their children to private schools and can only choose to leave their children behind in the countryside. In comparison, the threshold for migrants' children to attend public schools in Wuhan is a little lower. Among migrant children of school age who accompany their parents in Wuhan, the percentage in public kindergartens is $21.7 \%$, in primary school it is $88.2 \%$ and for middle school it is $93.1 \%$. These figures are much higher than they are for Beijing, Shanghai and Guangzhou.

Another central policy with regard to migrant education that local governments have "suspended" is that of allowing students from outside the city to take the university entrance test. According to the requirements of the Ministry of Education, every province was supposed to bring out policies to enable children from outside the province to take the university entrance test by the end of 2012 and the goal of this was to remove the restrictions on the children of migrants taking the college entrance test away from home. The requirement of the Education Ministry was quite vague, and did not stipulate specific indicators, which left room for local governments to put the policy on hold. However, the behavior of many local governments is really not in accordance with the ministry's requirements at all. By the end of 2012, local governments in various places had introduced some related policies, but the result is that in provinces in which there are few migrant workers, the restrictions on outsiders taking the college entrance test are fewest, and the situation is most relaxed, for example, provinces like Jiangxi and Heilongjiang. And provinces with a lot of migrants are basically taking measures to deal with the situation but have not made any substantive measures to adjust or change.

This includes cities like Beijing, Shanghai and Guangzhou. At the end of 2012 Beijing announced a "transitional plan" and promised to bring out a formal plan in 2013, but it is impossible to predict whether a formal plan will be produced or what it might be. The transitional plan has not opened up access to the university entrance test; it just stipulates that students with an outside hukou who meet the requirements can register for the middle level professional school test, and starting in 2014 they can be accepted for the high level professional school test. But there is no schedule yet for when they will be able to take the university entrance test. Shanghai published a plan to open up its policy in 2014. The plan's main content is that starting from 2014, children of migrants who hold A type residence permits, who took a part in the high school entrance test in Shanghai and who have completed their whole high school education in the city will be able to register for the university entrance test in Shanghai. But according to Shanghai's residence permit system, only outsiders who have a university education can get a type A residence permit. So from this we can see that the so-called relaxation of Shanghai's university entrance test policy has no meaning at all for migrants from rural areas. Guangdong Province seems to be taking bigger steps in the direction of opening up, but from the point of rural migrants, it still does not have much substantive meaning. From 2013, children of outside workers who have obtained hukou through the point system can register for the university entrance test. But the criteria for getting residence through the point 
system are also very tough. And basically most rural migrants have no hope of getting a hukou this way. Of course, what is an improvement over Beijing and Shanghai is Guangdong's promise to further open up the system in 2016. But it is not clear if the conditions will allow for relaxation. Of the four cities, only Wuhan has promised that it will open up the right for children of migrants to take the university entrance test in 2013.

The situation regarding the implementation of the "Labor Contract Law" is even less optimistic than it is for education policy. The Labor Contract Law stipulates that overtime cannot exceed $3 \mathrm{~h}$ a day, and total overtime cannot exceed $36 \mathrm{~h}$ a month; overtime pay and pay for working on holidays should be three times the regular wage; when hiring labor a labor contract must be signed, etc. But in fact, it is extremely common for rural migrants to exceed the overtime limits, and the rate of signing labor contracts is still very low. In 2013 our survey results showed that $57.2 \%$ of migrants worked 7 days a week, compared with only $11 \%$ of those with a hukou, $61.2 \%$ worked for more than $8 \mathrm{~h}$ a day compared with $19.1 \%$ of people with hukou, The State Council has brought out a whole series of policies relating to employment training and services, but the survey shows that only an extremely small percentage of migrants can enjoy the benefits of these policies. The situation in Beijing is also not very good: almost $60 \%$ (59.6\%) of respondents were individual workers or businessmen, and if another $22.3 \%$ who are working in private enterprises are added to this, the two account for $81.9 \%$ of the whole sample. $86.5 \%$ had no social protection at all; $67.9 \%$ of employees had not signed a labor contract with their employers and $37 \%$ of employers and independent workers were operating without a license; 17.4\% were using other people's licenses (Yuan and Yin 2009). Surveys have shown, that in Shanghai in 2008, the percentage of employer work units that had signed labor contracts with workers was as high as $98.5 \%$ (Jianfei and Youcheng 2008). Although this figure is questionable, it still shows to a certain extent that Shanghai has been relatively good in terms of implementing the labor law.

Another form of interpretation and adaptation is preempting (yushe). If suspension is a practice that involves not implementing central policy without giving any reason, then preempting is a practice that involves giving a reason for not implementing policy. It entails the local government setting a very high threshold for implementing central policy so that it restricts the target group of the policy. If "suspension" can be seen as a situation in which "the names are in accordance but the practice is not", then preemption can be seen as a situation in which "the names are in accordance but the practice does not achieve much". Regardless of whether it is Shanghai or Beijing, or Guangzhou or Wuhan, with regard to migrant workers enjoying local benefits, all these governments have established some preemptive conditions including stable and legal employment and legal residence. For children to attend school they also have to show a guardian's certificate, as well as the parents' employment and family planning certificates, as well as participation in social protection programs. These conditions have to a great degree prevented rural migrant workers from enjoying their legal rights and gaining access to basic social benefits. This is because many rural migrant workers are engaged in informal economic activities in the city and they cannot produce employment certificates. Many 
of them also live in very basic housing and do not have rental agreements. In this situation their children are prevented from enjoying their right to compulsory schooling and they themselves cannot take part in (or can only participate in some) social insurance schemes. Of course, the preemptive conditions that cities set are different. Some cities basically do not offer support for policies to provide social benefits to rural migrant workers in the informal sector. And some cities provide some support for these policies, while other cities allow migrants to meet some of their needs for social protection through the market.

In any event, the implementation of central government policies towards migrants at the local level is certainly not $100 \%$ and there is a significant implementation gap. On the one hand this is because "although the law is set by the central government, local government has a lot of room for interpretation. And because the difference between localities is very great, the central government allows localities to make different interpretations of the law" (Zheng 2013, p 8). Specifically, central policies always relate to principles, and they require local government to formulate and implement detailed regulations in accordance with local circumstances. At the same time, China lacks a scientific mechanism for evaluation, and this provides the basis and the space for local government to engage in "suspension and preempting" practices. On the other hand, local governments are all pursuing certain interests, and will find reasons or excuses for reducing the pressure from higher levels of government.

To take the four cities discussed here as an example, because Beijing is the capital, it is more inclined to emphasize social stability, and so increasing government control of migrants has become the first goal of policy. While Shanghai is seeking to become a world class center for financial the finance industry and services and so comparatively, opening up employment is more important. Guangzhou is a pioneer in introducing and experimenting with market-oriented reforms, and so marketization and commercialization have to certain extent affected government behavior. Wuhan is a large hinterland city which is now trying to increase the pace at which it catches up with the developed cities on the coast, and so it urgently needs more labor to serve this goal. Its migrant population also comes mostly from within the same province, and so it also has more reasons to allow migrants to enjoy similar social policies to urbanites. Based on these kinds of goals and interests, each locality has demonstrated different policy directions and preferences. And so they have adapted and implemented central policies that are beneficial to their locality, and suspended or preemptively adapted other policies.

\section{Discussion}

This article analyzed the four cities of Shanghai, Beijing, Guangzhou and Wuhan in order to understand the mechanisms that influence local governance with regard to the realization of migrants' citizenship rights. Here, I want to be clear that within the whole landscape of citizenship rights in Chinese society, migrants' rights are only one piece of the picture. But according to our analytical framework we can see that the realization of citizenship rights in China does not just depend on central 
government policy, but is also constrained by local governance, and different localities have different performance with regard to governance.

Beijing's type of governance is one of control-service. That is to say that the opening up of the hukou has been very slow and cautious and from the point of view of migrant workers it is almost impossible for them to gain a Beijing hukou. Beijing has also not yet introduced a residence permit or point count policy. But Shanghai, Guangzhou and Wuhan have introduced more reform and opening up with regard to the control of the hukou than Beijing, and have at least opened up a narrow pathway for migrants to move towards obtaining a hukou. The width of this pathway different in different cities: Wuhan is a bit broader than Guangzhou, and Guangzhou is broader than Shanghai. In keeping with this, the three cities are also different in their approach to social protection for migrant workers: Wuhan is more inclined to allow migrant workers to enjoy social policy benefits, Guangzhou is more inclined to let the market play the major role, and Shanghai has set up different kinds of treatment for different kinds of residency situations. From this we can see that Wuhan's model of local governance is more inclined towards the open-service type, Guangzhou is more inclined towards an open-market, and Shanghai is more inclined towards the control-service type but compared with Beijing it is still closer to an open-service type. If we can say that the open-service type of governance is the final, ideal goal that China's social reform and the social inclusion of migrants is aiming for, then we can see that in terms of realizing migrant workers' citizenship rights, of the four cities, Wuhan is out in the lead, followed by Guangzhou, Shanghai and Beijing, in a pattern of flying geese.

However, that is not to say that Wuhan has already realized citizenship rights for migrant workers. In fact, none of these four cities or any other in China has done this. Although the content of citizens' rights is very rich, and not exactly the same across different countries or even within the same country at different time periods, nonetheless, with the progress of economic and social development, there is a trend towards agreement on the content of citizen rights, as well as social rights. That is to say, no matter what, it is already internationally recognized that citizens' rights are the basic rights that citizens enjoy in any country; to use the words of Jing Tiankui, they constitute a "bottom line of equality". This kind of "bottom line of equality" or social welfare has not been realized all over the country. Different local government models have displayed different perspectives on social rights, and there is a phenomenon of localization, which we have called local welfare "regimes". Local welfare regimes are a bit like work unit benefits in having clear boundaries, but as reform and opening up progresses these boundaries are also gradually relaxing, because different models are appearing. From this perspective, the kind of governance model that is adopted reflects the need to protect local welfare.

Local welfare benefits can be considered in relation to national welfare benefits. If citizens' rights are the basic eligibility criteria for enjoying national welfare benefits, then local residents' rights or city residents' rights (or hukou eligibility) become the eligibility criteria for enjoying local benefits. Local welfare benefits are composed of three dimensions: economic benefits, government finances, and residents' benefits. From the analysis of these four cities we can see the following phenomena: First, the better a city's social benefits are, the less open it is towards 
migrants. Second, cities in which migrants from the city's own jurisdiction make up the majority are more open to migrants. Third, cities are most willing to welcome those migrants who can make the biggest contributions to their welfare, and rural migrants are likely to make a smaller contribution so they have not been considered a priority group for inclusion. Four, benefits that are to be supported by government finances are even harder to extend to rural migrant workers. For example, the costs of migrant workers' children's compulsory education are largely borne by the government. But the transfer payments from the Ministry of Education do not reach the governments that are receiving migrant children. As a result, from the point of view of the receiving governments, providing education for children of migrants is an extra budgetary burden. Local government thinks that financial resources at its own level should be used to provide benefits for people within its own jurisdiction, and not be made use of by people from outside. Finally, cities in which maintaining the current level of benefits is a priority and there is not much room for expansion are inclined not to provide benefits for migrants, for example if the quota of places in the university entrance test is fixed and there will not be much change. This is why it is particularly difficult to open it up admission to migrant workers' children.

From this we can see that local welfare has become a major factor for consideration in determining local governance models. Regardless of whether it is government or enterprises, local residents or social organizations, the first thing they are concerned about is improving local welfare. If giving social welfare benefits to rural migrants is within the scope of improving local welfare, then it will be implemented better. If not, even if the central government indicates that migrants should be given the same rights as local residents, local governments will not actively implement these policies but will instead use various kinds of adaptation to set up restrictions and barriers. Local governments will not think about the problem of universalizing citizens' rights. If migrants' citizen rights are actually going to be realized, the central government will still have to push forward the current reform of the social system, in order to ensure that migrants can secure their basic rights as citizens.

\section{References}

Jianfei, L., \& Youcheng, R. (2008). The implementation of the Labor Contract Law increases the rate of signing labor contracts. http://www.china.com.cn/law/txt/2008-12/25/content_17008199.htm.

Shogo, T. (2011). Sociology of welfare state. Beijing: The Commercial Press.

Solinger, D. J. (2009). Contesting citizenship in urban China. Hangzhou: Zhejiang People's Publishing House.

Yimingedt, Z. (2009). Social policies related to migrant worker in China. Beijing: China Labour and Social Security Publishing House.

Yuan, L., \& Yin, Z. (2009). Settlement intention and behavior of migrants in Beijing: a survey report (abstract). http://www.counsellor.gov.cn/content/2009-01/20/content_2154.htm.

Zheng, Y. (2013). De facto federalism in China: reforms and dynamics of central-local relations. Beijing: Oriental Publishing House. 


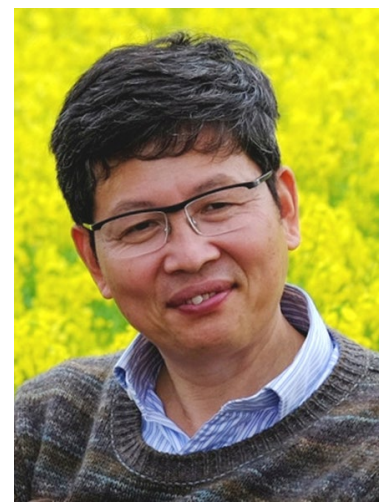

Chunguang Wang Chungguang Wang received M.Sc in Sociology from Nankai University, China in 1988 and Ph.D in Sociology from Graduate School of Chinese Academy of Social Sciences, China in 1994. He is professor and deputy director, Institute of Sociology at Chinese Academy of Social Sciences, President of Chinese Association of Rural Sociology, and Vice President of Chinese Association of Social Policy. His current research interests include social stratification, social structure, and social policy. 